\title{
Transient Spaces: Building Community in Crisis Contexts Project
}

\author{
LOUKIA TSAFOULIA
}

City College of New York

Transiency no longer appears as a condition of exception, but rather as the predominant mode of existence. The increased tension across and beyond national borders and territorial divisions has drawn the attention of designers across the globe and densified our reflections on questions of identity, equality, politics and economic exchange, expanding the reach of design from the realm of physical forms, into modes of interaction in social spaces.

The project presents design outcomes from the research conducted and methods employed during the advanced architectural design studio I developed and taught at the CCNY during 2017. The studio triggered an international call for contributions and it is currently under development for a book publication that explores the concept of impermanence in global contemporary society and aims to stimulate conversations about the potential of a new public realm.

The studio developed strategies for disaster response that show economic and social sustainability through community integration strategies. It concerned the design of community driven, systems approach and provided alternative ways for addressing everyday, context-based issues that are less dependent on the global relief industry. How can design disrupt power structures in relief response?
Could our methods adopt to the ever-increasing need for sheltering amidst ongoing crisis? How can architects optimize the capacity of people in acute need of protection while ensuring a high degree of livability and a sense of community and equality? These are some of the questions the studio addressed. Issues of temporality and space adaptation were investigated. The tactics of appropriation, severance, fragmentation and cultural identification of urban space were examined as, simultaneously, forces and reactions in the physical space in order to construct an ideological position.

The research and design investigations used as case studies four distinct sites in Athens, Greece. The selection was based on various degrees of temporality ranging from hyper-temporal hotspots to spontaneous or planned refugee camps and outside of camp contexts such as dense urban settings. In the outskirts of Athens, "Schisto" a former military camp, and "Skaramagkas" a former shipyard facility, are newly developed camps in the size of small towns hosting people for unknown amount of time. In the center of Athens, the studio engaged with the "Eleonas" Camp, a former industrial neighborhood and the "Prosfygika Alexandras" complex, built to host the 1922 Asia Minor disaster refugees and currently partially abandoned and appropriated by squats.

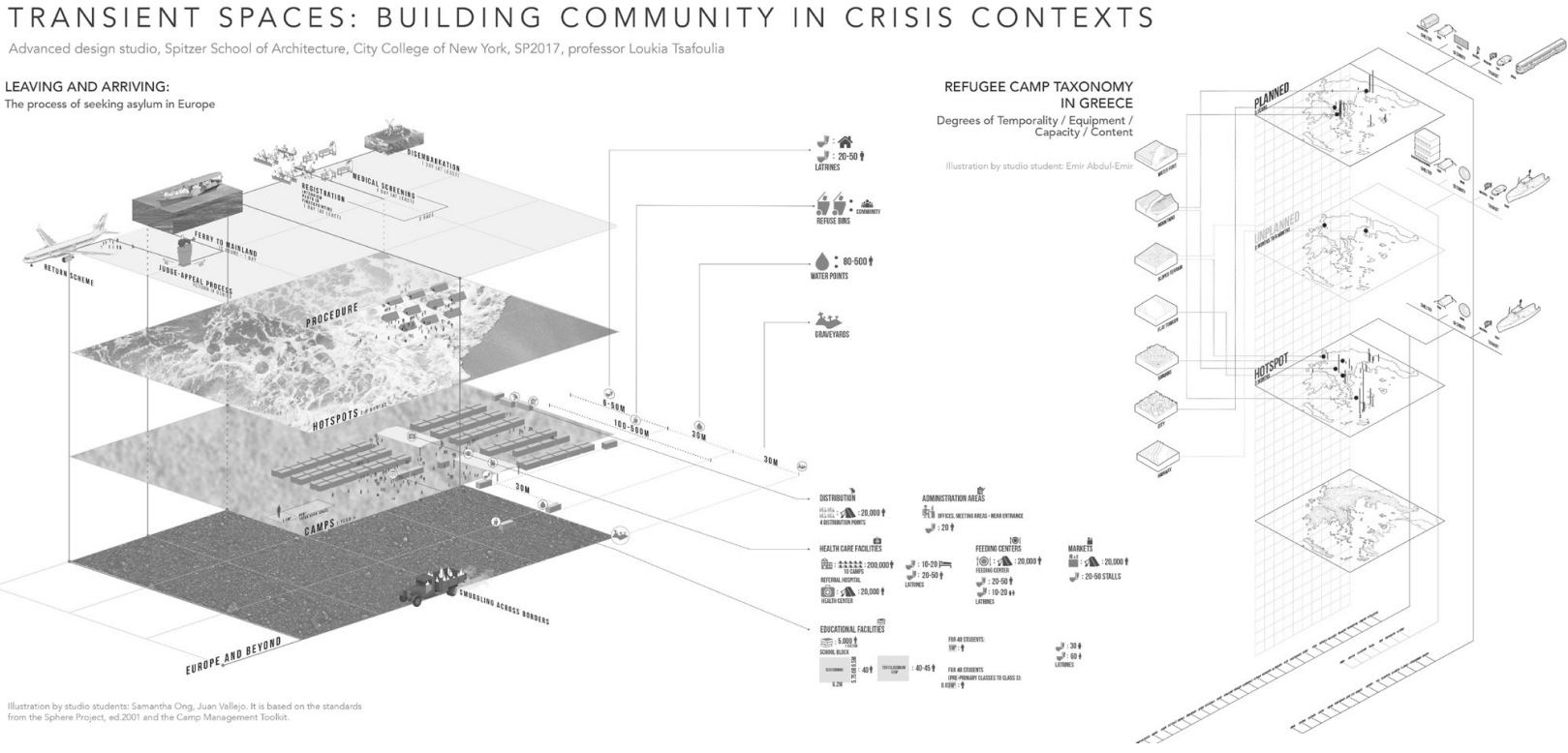


In an effort to establish bridges between academic research and the various professionals involved in the humanitarian support mechanisms, the studio connected with members from the Danish Refugee Council, the Greek Ministry of Immigration Policy and the UNHCR. This interdisciplinary inquiry inspired the book publication, as a way to rethink disciplinary boundaries, to identify radical tools and to construct ideological positions that do not contempt, but rather acknowledge and respond to contemporary tropes of instabilities, precarity and transience. As a curated collection of academic and creative probes the publication surfaces possibilities of operations, tactics, media and methods as a way of research and creates a dialog, generates knowledge and awareness.

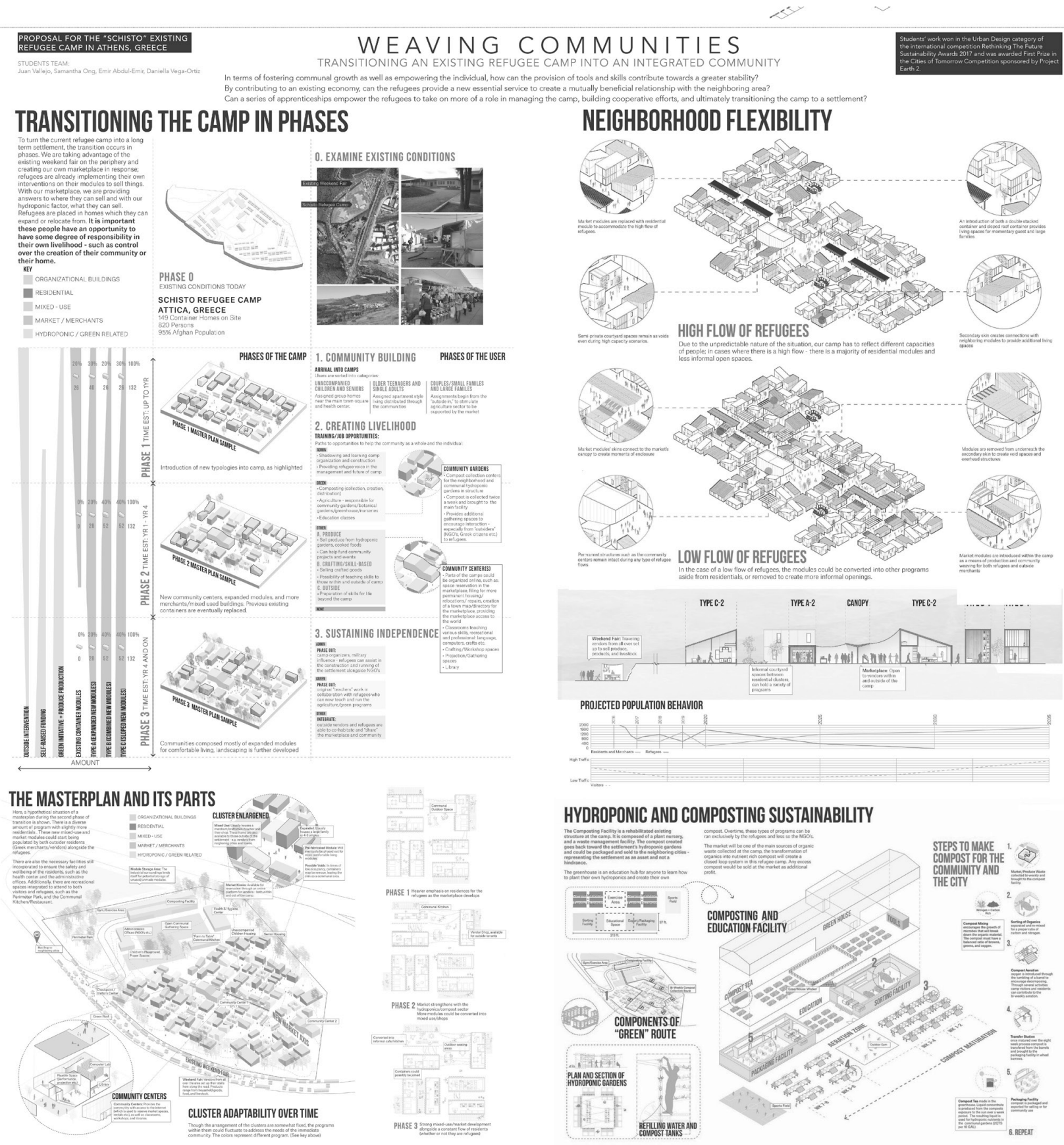

